\title{
Successful Spinal Anaesthesia in Patient of Achondroplasia Undergoing Lower Segment Cesarean Section
}

\author{
Vinod Kumar Srivastava ${ }^{1}$, Sumita Kumari ${ }^{2}$, Shefali Gautam ${ }^{3}$, Rita Wahal ${ }^{4}$ \\ ${ }^{1,2}$ Senior Resident, Department of Anaesthesiology, King George's Medical University, Lucknow \\ ${ }^{3}$ Assistant Professor, Department of Anaesthesiology, King George's Medical University, Lucknow \\ ${ }^{4}$ Professor, Department of Anaesthesiology, King George's Medical University, Lucknow
}

\begin{abstract}
There are more than 100 different types of dwarfism. Achondroplasia is the commonest form of dwarfism is associated with several bony changes in face, neck, spine, and can also have neurological and cardiopulmonary complications. Thus it presents several challenges to the anaesthesiologist as selecting anaesthetic technique. The aim of this report is to describe the anaesthetic consideration and problem encountered in management of these patients and preference of spinal anaesthesia over general anaesthesia. We report a 25 years old full term primigravida an achondroplastic parturient $126 \mathrm{~cm}$ tall, weighing $39 \mathrm{~kg}$, with 38-week pregnancy presenting with non-reactive non stress test and fetal distress where spinal anesthesia was used for emergency cesarean section. We used low dose spinal anaesthesia and did not encounter any problem regarding procedure and level of block.
\end{abstract}

Keywords: Achondroplasia; Dwarfism; Cesarean section; Spinal Anaesthesia; General Anaesthesia

\section{Introduction}

Dwarfism is defined as the failure to reach a stature over $148 \mathrm{~cm} \mathrm{[1]} \mathrm{and} \mathrm{achondroplasia} \mathrm{is} \mathrm{the} \mathrm{most} \mathrm{frequent} \mathrm{cause}$ which results from abnormal cartilage formation at epiphyseal growth plate. [2] Various uncommon disorder may be present in pregnancy that affect course of fetal development and pregnancy and anaesthetic management during cesarean and normal delivery. Achondroplastic dwarfism is one of these disorders and the clinical management remains controversial. [3]

Achondroplasia dwarfism (AD), the most common skeletal muscle dysplasia and cause of dwarfism.[4] $\mathrm{AD}$ is an autosomal dominant trait with $100 \%$ penetrance and large number of cases resulted from spontaneous mutation. Diagnosis is made at birth and is clinically based, with radiographic confirmation.[5] Endochondral ossification is decreased secondary to G-to-A substitution in fibroblast growth factor receptor 3 (FGFR-3) located on nucleotide 1138, adversely affecting the growth plates.[6] Dysplastic features include rhizomelic shortening, spinal kyphosis, lumbar lordosis, and spinal stenosis.[7] Females are affected more frequently than males.These patients have peculiar facial features, bony deformities and systemic abnormalities that often make administration of anesthesia challenging. [8] These individuals have normal mental and sexual development and life-span may also be normal.

The achondroplastic parturient has a high likelihood of delivery by cesarean section due to cephalopelvic disproportion hence anesthesiologist involvement is very crucial.

\section{Case Report}

A 25 year old female G1P0 with 38 week pregnancy was admitted in Obstetrics \& Gynaecology emergency department with complaint of decreased fetal movement. Non stress test (NST) was done and it showed non reactive. Patient was planned for emergency lower segment cesarean section.

Patient was completely examined and proper history was taken before shifting in operative room. She was assessed head to toe. She was dwarf with height of $126 \mathrm{~cm}$ and weight $39 \mathrm{~kg}$. Her head was large with short limbs and scoliotic lower spine (Fig.1\&2). Airway was normal with MPG 1, mouth opening 3 fingers breadth, but slight limitation of neck movement was present. On auscultation there was bilateral equal air entry with normal vesicular breath sound. Heart sounds was normal with no added murmur.

She had no respiratory or cardiac complaints. She had no previous surgery and her all three trimesters were uneventful. She was diagnosed case of achandroplasia by her previous documents. Her fasting hours was around 4 hrs.

After taking written and explained consent patient was shifted in Operation Theater. All anaesthesia option were described to the patient. The technical difficulty of regional anaethesia and all complication and issue concerned with general anaesthesia were also discussed with surgical team. Patient agreed for spinal anesthesia though she was told of its technical difficulty and complication in her case and chances that general anaesthesia could be given in any point of time. 


\section{International Journal of Science and Research (IJSR) \\ ISSN (Online): 2319-7064 \\ Index Copernicus Value (2013): 6.14 | Impact Factor (2014): 5.611}

Monitors including NIBP, pulseoximetry, ECG was attached. Blood pressure showed reading of $110 / 80 \mathrm{mmHg}$ pulse of $100 / \mathrm{min}$ with sinus rhythm and saturation $99 \%$ on room air. She was catherised with 14 french size foley's catheter. Intravenous peripheral line with $20 \mathrm{G}$ cannula was taken in both arm and $500 \mathrm{ml}$ of crystalloid fluid was infused. She was premedicated with iv $4 \mathrm{mg}$ ondensetron,50 $\mathrm{mg}$ rantidine and $10 \mathrm{mg}$ metoclopropamide. She was given spinal anaesthesia in L4-L5 space by $25 \mathrm{G}$ spinal needle with dose of Bupivacaine heavy $8 \mathrm{mg}$ and $25 \mu \mathrm{g}$ fentanyl in sitting position. She was made to lie down after 20 second to avoid sudden increase in height of block and wedge was put under right hip. Sensory blockade was achieved till $\mathrm{T}_{6}$ after 2 minute. The patient was prepped and draped. Before surgical incision level was against checked and was found to be same level at $\mathrm{T}_{6}$.

Surgery was uneventful with delivery of male baby of birth weight $2.4 \mathrm{~kg}$ with Apgar score 6,7 and 9 at birth, 5 minute and 10 minute respectively and no apparent skeletal deformity. Inj. Oxytocin was given after delivery and clamping of umbilical cord done. Intraoperatively Systolic blood pressure ranged from 96 to $120 \mathrm{mmHg}$, diastolic pressure from 60 to $86 \mathrm{mmHg}$ and Pulse from 90 to 120 /minute. Total $1500 \mathrm{ml}$ fluid was given with blood loss of about $500 \mathrm{ml}$ and urine output about $150 \mathrm{ml}$.The patient was stable during the intraoperative, postoperative period and discharged 7 days later.

\section{Discussion}

Achondroplastic dwarfs characteristically have low fertility rates; however, when they conceive often require delivery by cesarean section. The achondroplastic pelvic inlet is characterized by having a narrow anteroposterior diameter, hence cephalopelvic disproportion is common and further aggravated if the fetus inherited the condition, since macrocephaly is very common. [9] Consequently, cesarean section is the most common form of delivery for these patients. Mask ventilation may be difficult secondary to macroglossia, poor dental occlusion and flat nasal bridge; these classic characteristics of achondroplastic patients makes face mask fitting difficult. [10] Mather described a case in which direct laryngoscopy was impossible secondary to a patient's inability to extend his neck. [11]

We found reports related with achondroplasia which had successfully managed by regional anesthesia. These are spinal, epidural or combined spino-epidural (CSE) techniques.

We have found in our institution that usual and customary dose of Bupivacaine for spinal anaesthesia in cesarean section is $12 \mathrm{mg}$. Dose of bupivacaine is further reduced for short and dwarf patient and level of block is raised slightly if administered in sitting position. Sensory blockade till $\mathrm{T}_{3}$ was obtained with $1.3 \mathrm{ml}$ of $0.5 \%$ hyperbaric bupivacaine given in the sitting position.[12] However, other than hypotension, no other serious adverse events, including the much-feared neurological deficits, have so far been reported.
We had decided only spinal anesthesia in our patient because of two reason. First general anaesthesia in emergency surgery may be risky due to lack of adequate preparation of patient, risk of aspiration along with anticipated difficult bag and mask ventilation and intubation because of large head and limited neck movement and since our patient have mild degree of scoliosis so there was less possibility of difficulty in anesthetic technique.

However spinal anaesthesia has been given successfully without any sequelae in my patient. The risk of general anaesthesia versus regional anaesthesia must be considered for each patient as severity of spinal abnormality can vary considerably.

\section{Conclusion}

The plan for general or spinal anesthesia should be based on each individual case. A complete history and physical examination can help in reducing the risk. Each case should be regular follow up from early prenatal to delivery. Prenatal diagnosis can be done by mutation detection at 10 12 weeks of gestation and 16-20 weeks by ultrasonographic examination. The most important point is proper and careful preoperative assessment.

\section{References}

[1] Laederich MB, Horton WA. Achondroplasia: pathogenesis and implications for future treatment. Curr Opin Pediatr. 2010;22:516-23.

[2] Tetzlaff JE. Skin and bone disorders. In: Anaesthesia and uncommon diseases. Published by Saunders. $5^{\text {th }}$ Edition 2006:327-29.

[3] Kuczkowski KM: Labor analgesia for the parturient with an uncommon disorder: A common dilemma in the delivery suite. Obstet Gynecol Surv; 2003;58(12):800-3.

[4] Orioli IM, Castilla EE, Barbosa-Neto JG. The birth prevalence rates for the skeletal dysplasias. J Med Genet. 1986;23(4):328-32.

[5] American Academy of Pediatrics Committee on Genetics. Health supervision of children with achondroplasia. Pediatrics 1995; 95:443-51.

[6] Francomano CA.The genetic basis of dwarfism. N Engl J Med. 1995;332(1):58-9.

[7] Yoshi J, Traynelis V MD. Achondroplasia and cervical laminoplasty. J Neurosurg Soine 2009;11:417-420.

[8] Berkowitz ID, Raja SN, Bender KS, et al. Dwarfs: pathophysiology and anesthetic implications. Anesthesiology 1990; 73: 739-59.

[9] Chetty SP, Shaffer BL, Norton ME. Management of Pregnancy in Women With Genetic Disorders, Part 1: Disorders of the Connective Tissue, Muscle, Vascular, and Skeletal Systems. ObstetGynecolSurv2011;66:699709.

[10] Monedero P, Garcia-Pedrajas F, Coca I, et al. Is management of anesthesia in achondroplastic dwarfs really a challenge? J Clin Anesth. 1997;9(3):208-12.

[11] Mather JS. Impossible direct laryngoscopy in achondroplasia. A case report Anaesthesia. 1966;21(2):244-8. 


\section{International Journal of Science and Research (IJSR) \\ ISSN (Online): 2319-7064}

Index Copernicus Value (2013): 6.14 | Impact Factor (2014): 5.611

[12] Ravenscroft A, Govender T, Rout C. Spinal anaesthesia for emergency cesarean section in an achondroplastic dwarf.Anaesthesia 1998;53:1236-7.

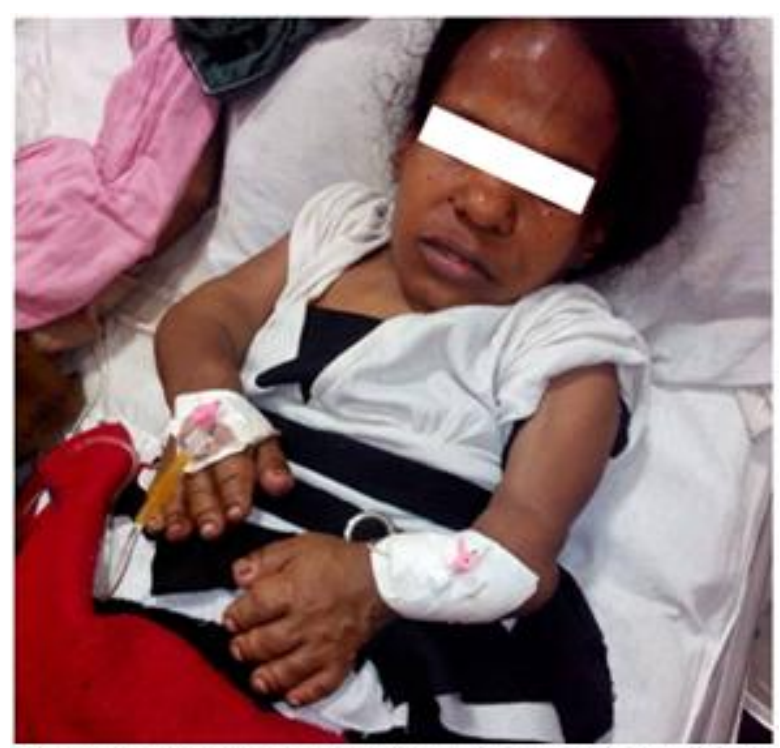

Figure 1. showing broad face, short neck and limbs

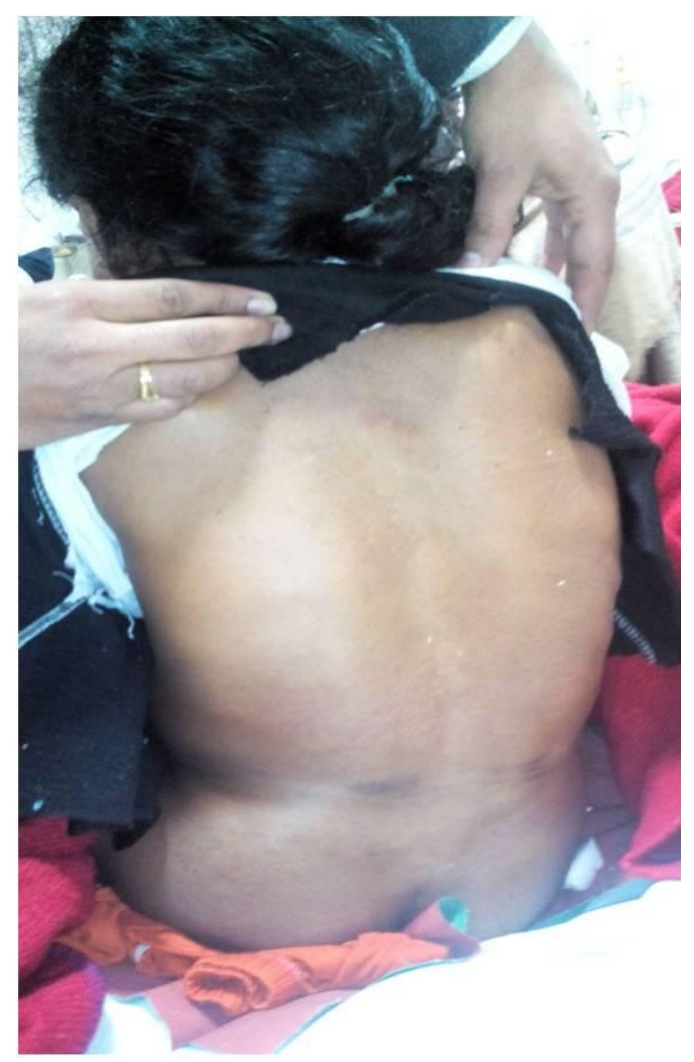

Figure 2: Showing Scoliosis

Volume 4 Issue 12, December 2015 www.ijsr.net 